\title{
Ocupações de terra: constelações entre o Caldeirão de Santa Cruz do Deserto no Ceará e as ocupações urbanas de sem-teto da região Metropolitana de Belo Horizonte
}

\section{Land settlements: constellations between the Caldeirão of Santa Cruz do Deserto in Ceará and the urban communities of homeless families in the Metropolitan Region of Belo Horizonte}

Luiz Fernando Vasconcelos de Freitas

Universidade Federal de Minas Gerais, Belo Horizonte, Minas Gerais / Brasil luizfernandovf28@gmail.com

Joviano Gabriel Maia Mayer

Universidade Federal de Minas Gerais, Belo Horizonte, Minas Gerais / Brasil mayerjoviano@gmail.com

Douglas Mosar Morais Resende

Universidade Federal Fluminense, Niterói, Rio de Janeiro / Brasil dougresende@gmail.com

Resumo: $\mathrm{O}$ presente artigo tem como objetivo estabelecer uma conexão entre o Caldeirão de Santa Cruz do Deserto, comunidade que foi aniquilada pelas forças públicas militares brasileiras em 1937, no Ceará, e algumas ocupações urbanas da região Metropolitana de Belo Horizonte no presente. Por via da análise do texto do espetáculo teatral 'O Caldeirão da Santa Cruz do Deserto', que representou esse massacre estabelecendo pontos em comum com as ocupações urbanas de sem-teto, e, por via de reflexões sobre o conceito de história em Walter Benjamin, busca-se afirmar a memória, a arte e a política como espaços de resistência, de combate ao esquecimento e de construção de novas sociabilidades.

Palavras-chave: ocupações urbanas; memória; comunidade; conceito de história; Caldeirão de Santa Cruz do Deserto. 


\begin{abstract}
This article aims to establish a connection between the Caldeirão of Santa Cruz do Deserto, a community that was annihilated by the Brazilian military forces in 1937, in Ceará state, and some urban settlements located in the Metropolitan Region of Belo Horizonte in the present time. By analyzing the theatrical piece named[acho que deve colocar em português mesmo, não?] 'The Caldron of the Holy Cross of the Desert', which depicts this massacre by establishing points in common with the homeless urban settlement, and through reflections on the concept of history in Benjamin the article seeks to claim memory, art and politics as spaces of resistance, combating oblivion and building new sociabilities.
\end{abstract}

Keywords: urban settlements; memory; community; concept of history; Caldeirão of Santa Cruz do Deserto.

Recebido em: 30 de agosto de 2017. Aprovado em: 6 de fevereiro de 2018.

\title{
1 Introdução
}

A relação entre propriedade fundiária e estruturas de poder no Brasil revela uma construção de desigualdade social já que a histórica concentração de terras retira da população brasileira a possibilidade de acesso ao substrato básico para o estabelecimento da dignidade humana, qual seja, o acesso à moradia e o uso da terra para produção de alimentos e para o trabalho.

Por essa seara compreende-se a propriedade fundiária como uma relação social de opressão tendo em vista que grandes parcelas da sociedade são excluídas do acesso ao mínimo existencial em virtude da terra ser considerada mercadoria na lógica de reprodução capitalista.

As ocupações de terras improdutivas são uma forma legítima de combater esse sistema de injustiça ao afirmar que toda terra tem que cumprir uma função social e que não pode estritamente servir expedientes de especulação imobiliária. Ocupar terras ociosas é uma forma de pressão popular para que haja a democratização do acesso à terra e das relações de poder. Por outro lado, não há que se falar em Estado democrático de direito sem a possibilidade de conflitos para a salvaguarda e a efetivação de direitos.

O presente artigo busca resgatar a história e memória de resistência da comunidade Caldeirão de Santa Cruz do Deserto, no Ceará, para 
em seguida abordar a forma de luta das ocupações urbanas na Região Metropolitana de Belo Horizonte no presente e, por fim, refletir como o teatro construiu uma constelação entre essas comunidades.

\section{Caldeirão de Santa Cruz do Deserto}

O Caldeirão de Santa Cruz do Deserto foi uma comunidade fundada em 1926, na região do Cariri, no Ceará. A comunidade tinha em sua direção José Lourenço Gomes da Silva, mais conhecido por beato José Lourenço, descendente de negros e considerado discípulo de Padre Cícero. Contra o poder do latifúndio e da vida liberal desafiaram a ordem estabelecida e pensaram uma sociedade mais justa e igualitária fundada no compartilhamento da terra e do trabalho. No Caldeirão, os imigrantes, romeiros e ocupantes trabalhavam todos em favor da comunidade e partilhavam cotas da produção coletiva.

A comunidade praticava o catolicismo popular, exercendo a fraternidade e solidariedade, e tinha como centralidade a redução da pobreza e das condições de privação a que estavam submetidas no sertão do Nordeste brasileiro por via do trabalho coletivo, da disciplina e oração. Como demonstra o excerto do Texto do Espetáculo: $O$ Caldeirão da Santa Cruz do Deserto:

BEATO: Foi-se esse tempo, irmãos. Aqui, entre nós: É a gente a fazê!/ Terra pra plantá/Roupa pra costurá/ todos pode ajudá/ com fé vamos firmar/ Vamos todos comer/ Nada vai nos faltar/ firmar com o coração/ disciplina e oração.” (ALBINATI; CHIARADIA, 2017, p. 5)

A história da política brasileira é marcada pela imposição de uma ordem que busca aniquilar todas as formas de organização coletiva, autônomas e popular tais como Canudos, Contestado e Quilombo dos Palmares. Não foi diferente com o Caldeirão que foi acusado pela sociedade conservadora de praticar o comunismo e do risco de criação de uma "nova Canudos." A construção da narrativa dos jornais da época mostra como esse discurso do fanatismo era manejado:

Dois malandros do Ceará, José Lourenço e Severino Tavares, andam manchando a memória do padre Cícero, no vale do Cariri. Os fiéis que eles atraem - pobres coitados alucinados pela seca - são obrigados ao trabalho 
e à penitência... São fanáticos, não resta dúvida! Fato é que José Lourenço e Severino estão desmoralizando a profissão de beato. Adaptado de O POVO, 02/03/1936, p. 2 (ALBINATI; CHIARADIA, 2017, p. 10)

Para além do aniquilamento físico o Caldeirão foi marcado pela tentativa de imposição do esquecimento, esquecimento de um massacre que ocorreu no Cariri em 1937 quando o governo Getúlio Vargas aliado ao governador do Ceará à época, Menezes Pimentel, executaram, inclusive com bombardeio aéreo cerca de 2.000 (duas mil) pessoas segundo dados da época sob a fundamentação da preservação da segurança nacional e da moral (ALBINATI; CHIARADIA, 2017, p. 26). Veja-se:

Viemos em nome do governador do Estado do Ceará, o senhor Menezes Pimentel, e do digníssimo Presidente da República, Getúlio Vargas. / Agimos em nome moral e da segurança nacional / Seguimos ordens, orientados por convicções de quem entende o que é e o que não é bom para todos! Só usaremos de força se necessário for. (ALBINATI; CHIARADIA, 2017, p. 10)

A história do Caldeirão não é difundida no imaginário social coletivo nacional e enfrenta o desafio e a tarefa histórica de não ser esquecida. Foi a primeira vez na história que a Força Aérea Brasileira (FAB) operou bombardeio contra comunidade dentro do próprio território nacional, sem qualquer chance de defesa. A memória nesse caso deve funcionar como espaço de resistência tendo em conta que esquecer pode ser permitir que outros aniquilamentos ocorram e lembrar é combater qualquer prática de aniquilamento de sujeitos, de identidades coletivas, de comunidades que buscam praticar outras formas de sociabilidade humana livres da opressão.

Paul Ricoeur coloca uma relação entre o dever da memória e o dever de não esquecer. Articulando as noções de rastro e esquecimento, o autor fala do risco que há em o rastro representar a destruição e o apagamento, como se vê na citação abaixo. No entanto, os símbolos da memória e da resistência devem promover uma constelação entre experiências de luta no passado e no presente, como se verá adiante.

O nosso terceiro e último problema diz respeito ao lugar do esquecimento no campo que é comum à memória e à história; deriva da evocação que acaba de ser feita do dever 
de memória: este pode ser igualmente expresso como um dever de não esquecer. O esquecimento é, certamente, um tema em si mesmo. Diz respeito à noção de rastro, de que falamos antes, e da qual tínhamos constatado a multiplicidade das suas formas: rastros cerebrais, impressões psíquicas, documentos escritos dos nossos arquivos. O que a noção de rastro e esquecimento tem em comum é, antes de tudo o mais, a noção de apagamento, de destruição. (RICOEUR, 2003, p. 6)

Nesse ponto convém mencionar a Tese V, Sobre o conceito de história, de Walter Benjamin, em que a verdadeira imagem do passado passa de forma furtiva e, como uma centelha, tem que ser capturada no instante em que vemos no presente, o que de fato se constitui como barbárie no passado:

\begin{abstract}
$\mathrm{V}$ - A verdadeira imagem do passado passa por nós de forma fugidia. O passado só pode ser apreendido como imagem irrecuperável e subitamente iluminada no momento do seu reconhecimento. "A verdade não nos foge": essa fórmula de Gottfried Keller assinala, na concepção da história própria do historicismo, precisamente o ponto em que essa concepção é destruída pelo materialismo histórico. Porque é irrecuperável toda a imagem do passado que ameaça desaparecer com todo o presente que não se reconheceu como presente intencionado nela. (BENJAMIN, 2012, p. 11)
\end{abstract}

Essa imagem como diz Michael Löwy, em Walter Benjamin: aviso de incêndio - Uma leitura das teses "Sobre o Conceito de História", tem por objetivo descobrir a constelação crítica que um fragmento do passado forma precisamente com um momento do presente (LÖWY, 2012, p. 62). Quais os pontos de conexão entre o caldeirão da Santa Cruz do deserto e as ocupações urbanas no presente serão trabalhados nos próximos tópicos.

\title{
3 Ocupações urbanas de movimento sem-teto na Região Metropolitana de Belo Horizonte
}

No Brasil há um enorme déficit habitacional que é a aferição de quantas casas faltam para atender os sem-casa. São milhões de pessoas 
que vivem em áreas de risco geológico, sujeitas à inundações, tendo um ônus excessivo com aluguel ou em coabitação. É o que aponta Guilherme Boulos, da Coordenação nacional do Movimento dos Trabalhadores Sem-Teto (MTST), no livro Por que ocupamos- Uma Introdução à luta dos sem-teto?:

O último estudo feito pela Fundação João Pinheiro (publicado em novembro de 2013), que é utilizado oficialmente pelo Governo, mostra que o déficit habitacional quantitativo no Brasil é de 6.940 .691 famílias, o que representa cerca de 22 milhões de pessoas que não tem casa. Os sem-teto são, portanto, mais de $10 \%$ da população do país. (BOULOS, 2004, p. 13)

Em Belo Horizonte há um déficit habitacional, segundo a Fundação João Pinheiro de cerca de 80.000 moradias (Fundação João Pinheiro, 2013). A política pública de habitação de interesse social gerenciada entre 2009 e 2016 por via do Programa Minha Casa, Minha Vida (PMCMV) não chegou a combater 10\% dessa carência de moradias enquanto as ocupações urbanas construíram, segundo estimativas de movimentos sociais da cidade, cerca de 25.000 moradias nos últimos 10 anos.

Ocupações urbanas como Rosa Leão, Vitória, Esperança, Guarani Kaoiwá, Tomás Balduíno e Dandara autoconstruíram milhares de casas por via do suor, da luta e da auto-organização comunitária em terrenos que não cumpriam a função social da propriedade e da terra e colocando em prática uma política comunitária de habitação.

A política de efetivação de direitos que têm maior relevância e se conforma como base estruturante para que se possa acessar outros direitos é o direito à moradia adequada. A partir desse direito garantido, que é o mínimo existencial para a dignidade humana, busca-se o exercício de outros direitos tais como acesso à saúde, educação, trabalho, saneamento, lazer e demais direitos sociais.

A permanência e consolidação dessas ocupações é sinal de que o contínuo da história, a visão evolucionista da história, não está se realizando e como afirma Michael Löwy, em comentário à tese IV Sobre o conceito de história: "O passado é iluminado pela luz dos combates de hoje, pelo sol que se levanta no céu da história." (LÖWY, 2012, p. 60) 
Nessa linha de ideias afirma-se que a luta das ocupações de semteto hoje ilumina e resgata a história de resistência do Caldeirão da Santa Cruz. É necessário abrir o passado a partir das resistências no presente e buscar a redenção daqueles que tombaram no Cariri no Ceará. Cada vitória hoje das comunidades autoconstruídas é uma forma de assegurar a justa memória dos que foram massacrados pela força do Estado na década de 1930.

A citada tese IV, Sobre o conceito de história, de Walter Benjamin fica claro como o passado almeja a redenção, tal como as flores se voltam para o sol: "Tal como as flores se voltam para o sol, assim também, por força de um heliotropismo secreto, o passado aspira a poder voltar-se para aquele sol que está a levantar-se no céu da história”. (BENJAMIN, 2012, p. 11)

As ocupações urbanas também estabelecem um modo de vida comunitário em que há coordenação de interesses para a reprodução da vida, manutenção e consolidação das comunidades. Assim como no Caldeirão o trabalho coletivo tem prioridade e busca-se estabelecer uma sociabilidade ética e comunitária para que novas relações sociais sejam construídas.

\section{Teatro e sua expressão política: a peça o Caldeirão de Santa Cruz do Deserto teatro nas ocupações de sem-teto da RMBH}

O espetáculo O Caldeirão de Santa Cruz do Deserto, viabilizado através do Prêmio Myriam Muniz de Teatro 2015, teve temporada nas comunidades Rosa Leão, Vitória, Esperança, Guarani Kaoiwá, Tomás Balduíno, Dandara, além do Espaço Comum Luiz Estrela, entre os dias 21 de Abril e 21 de Maio de 2017. Com concepção de Bruna Chiaradia e Direção de José Walter Albinati a sinopse e o histórico da peça foram apresentados da seguinte forma:

Um pedaço de chão, um canto de mundo, um povo que caminha. O Caldeirão da Santa Cruz do Deserto foi uma comunidade liderada pelo Beato José Lourenço, sob a orientação de Padre Cícero, nos anos 30 . A região, em plena seca no sertão do Ceará, era abastecida por um único poço: o "Caldeirão". O trabalho era distribuído entre todos - sem exploração. E repartiam o que tinham entre si. Os poderes locais combateram violentamente essa ocupação pacífica, 
espalhando o boato de que dali surgiria uma rebelião: uma "Nova Canudos". A comunidade foi bombardeada em 1937. Em 2017, esse episódio, literalmente queimado dos registros da história oficial, completará 80 anos. Rememorá-lo, em paralelo às atuais ocupações, é um manifesto reflexivo sobre as lutas por terra, por moradia e pelos direitos em nosso país. (ALBINATI; CHIARADIA, 2017, p. 3)

Chama a atenção nesse trecho que a fonte de água em plena seca no sertão era o "Caldeirão" que funcionava como território de acolhida para retirantes e pessoas que passavam pelas privações da fome e que tinham a oportunidade de um modo de vida digno por via do acesso à terra e ao trabalho. Além disso, apresentar a peça nas ocupações urbanas é uma forma de construir a memória e a luta do que são essas comunidades como espaços de resistência.

Michael Löwy afirma que Benjamin pensa em constelações que interconectam passado e presente formando mônadas, instantes plenos de totalidade histórica:

A rememoração tem por tarefa, segundo, Benjamin, a construção de constelações que ligam o presente e o passado. Essas constelações, esses momentos arrancados da continuidade histórica vazia, são mônadas, ou seja, são concentrados da totalidade histórica - plenos, diria Péguy. (LÖWY, 2012, p. 131)

Os momentos em que se pode estabelecer uma constelação entre o passado de forma articulada com o presente envolvendo o Caldeirão de Santa Cruz do Deserto e as ocupações urbanas apareceram em vários momentos da peça de teatro. Importante citar algumas dessas passagens como a que abre o espetáculo:

NARRAÇÃO: Dizem... Dizem que "Deus inventou a terra... (mostrando as mãos em concha) e a besta fera lavrou a escritura." Um pedaço de chão. Um canto de mundo. O que é que você quer? O que é que você tem? O que é que eu quero? Eu só quero...Um tanto de terra. Pra gente plantar, levantar parede, colocar um teto, dar nome de lar. Terra. Pra criar galinha, boi, cachorro, porco... gato, codorna, filharada, pra criar afeto, história e raiz. De 
quem é a terra? Qual o nome do dono? Quem doou? Quem comprou? E quanto foi...que isso custou? Quem passou a escritura, de papel passado e tudo? Qual o papel da terra? Tem quanto de terra nesse tanto de mundo? Então será que a terra...foi tomada? Herdada? Quem pagar mais... leva? E quem trabalhar mais? Como foi isso, antes de tudo, antes de hoje, antes de nós? De quem era a terra? A terra Brasil? Terra sem dono ou era...terra de índio? Cadê o índio? Pra onde ele foi? Pra onde 'foram' com ele? Um pedaço de terra pra todo mundo nesse tanto de mundo, me conta se tem?!De quem é essa terra? Nossa? É sua? É minha também? (ALBINATI; CHIARADIA, 2017, p. 1)

As questões levantadas nesse trecho são questões que perpassam todo o histórico de luta e acesso a terra no Brasil. A necessidade material e espiritual do povo de ter uma terra para plantar, criar os filhos, criar afetos e raízes - realizar o sonho de ter um lar com estabilidade - aparece em toda a nossa história. E por outro lado aparecem em tensão a usurpação das terras, as expulsões, despejos, grilagem e todo tipo de apropriação e financeirização do que deveria ser um bem comum.

Em outro momento da peça outras indagações são feitas em torno do risco de despejo forçado e das possibilidades de retomada da luta. Essa é uma possibilidade real para todas as ocupações - a ameaça de uma ação militarizada que aniquile sujeitos políticos e que destrua as comunidades. Veja-se:

De quantos lugares já fomos expulsos? Quantos despejos sofremos? E as vigílias? E os medos? E a gente ocupa de novo. Ocupa tudo! E assim vai... Eles não dão sossego. A gente também não vai dar. A luta é igual um rio, não para nunca. Nem quando seca. Porque segue ecoando. "Quem não pode com a formiga, não assanha o formigueiro." (ALBINATI; CHIARADIA, 2017, p. 26)

E ainda convém citar um trecho que deixa claro o momento de despejo, uma reintegração de posse que se torna uma desintegração de sonhos com o total aniquilamento da comunidade:

TODOS SOLDADO/BESTA FERA: Se vocês conseguirem entender que acabou essa fanfarrice de Caldeirão, já está de bom tamanho. Isso é uma ação de 
despejo! Isso é uma reintegração de posse. Isso é a lei! É a manifesto da vontade dos que podem ter vontade nessa terra. Viemos combater! Estraçalhar! Esquartejar! Desocupar! Reapropriar! Limpar! Exterminar! Apagar! Queimar! Despejar! Golpear! (ALBINATI; CHIARADIA, 2017, p. 28)

Esse momento de perigo, esse aviso de incêndio na tradição Benjaminiana, é o momento no presente em que a imagem de uma brutal repressão no passado pode se fazer realidade. No momento em que era encenado o despejo do Caldeirão nas comunidades percebia-se a emoção que pairava no ambiente, mas a mensagem de que a luta é igual um rio é uma mensagem mais forte e que prevalece na memória coletiva.

A posição dos órgãos instituídos quanto à reintegração de posse também é uma questão a ser colocada. Nesse ínterim a produção da peça articulou memórias das ocupações hoje com a cena histórica do Caldeirão ao afirmar que o juiz dormiria com a consciência tranquila, mesmo após as mortes, fato que, segundo relatos orais dos moradores das ocupações da Izidora aconteceu em um julgamento na corte especial do Tribunal de Justiça de Minas Gerais. O trecho é o seguinte:

Sobreviventes garantem que mais de 2000 ocupantes foram exterminados neste ataque aéreo. Afirmando ser boato, a PM e o Exército apresentam estatísticas na faixa de apenas uma centena de fanáticos. Em depoimento à imprensa, um coronel esclareceu que não se pode acreditar nesses 'caderninhos de cadastro' feitos pelos desocupados e que tinha orgulho de proteger Juazeiro dessa corja de baderneiros preguiçosos. Um juiz, que aprovou a ação, declarou: "Vou deitar minha cabeça no travesseiro com a consciência tranquila. Eles foram alertados". (ALBINATI; CHIARADIA, 2017, p. 30)

A peça termina com um ato de profissão de fé em que se celebra a força das ocupações e resistências que formam uma grande constelação de lutas que enfrentam os poderes constituídos:

A7 e revezamento dos demais: ...bravos voluntários. Porque desse céu, que choveu bomba em cima dum povo justo, dizem, já choveu foi maná! Pão de sustança divina que botava de pé, uma gente peregrina no deserto, em 
busca de ver cumprir a promessa de ser livre um dia na vida, num canto nesse chão. De quem é a terra? Essa, na qual o corpo, casa, engenho e esperança desabam? $\mathrm{Na}$ qual uma bomba despenca? Terra onde me apoio e levanto, pra reconstruir tudo de novo e seguir pisando firme, em frente com a luta, como aquele povo que já foi Baixa Danta e se tornou Caldeirão, que ressurgiu no Sítio União e hoje quem é? Agora que nome tem? Se chama Dandara, Areias, nação Guarani Kaiowá... É Izidora: Rosa Leão, Esperança e Vitória. É a Comunidade Quilombola de Luízes, é Pinheirinhos, é o CRJ - Centro de Referência da Juventude. Onde nosso corpo luta, labuta e até dança, com fé na lida, por outra vida, aqui e agora, para o futuro e adiante: com o desejo de vivermos, neste país, nosso grande Sítio Caldeirão, porque essa nação...

Resposta: A coragem de vocês fortalece a nossa luta. (ALBINATI; CHIARADIA, 2017, p. 35)

O trecho retoma a história do Caldeirão de Santa Cruz do deserto que passa pela ocupação da Baixa Danta até o Sítio União e que se conforma como várias ocupações seja no campo ou nas cidades. Jeanne Marie Gagnebin, no livro História e narração em Walter Benjamin, afirma que a rememoração do passado implica em uma transformação do presente:

a saber, que a exigência de rememoração do passado não implica simplesmente a restauração do passado, mas também uma transformação do presente tal que, se o passado perdido aí for reencontrado, ele não fique o mesmo, mas seja, ele também, retomado e transformado. (GAGNEBIN, 2004, p. 16)

Assim, fazer memória do Caldeirão da Santa Cruz do Deserto por via do teatro não implica somente em denunciar a barbárie que aconteceu, mas também afirmar no presente que as ocupações e comunidades populares são uma alternativa histórica e legítima para milhares de famílias acessarem uma vida digna e, com isso, proclamar a tradição dos oprimidos em buscar suas próprias formas de libertação e redenção. 


\section{Conclusão}

A história do Caldeirão de Santa Cruz do Deserto é uma memória em aberto de várias comunidades-ocupações desse nosso Brasil que retomam um pedaço de chão para em luta fazer um novo mundo.

De um lado, o trabalho coletivo, a resistência partilhada e uma nova sociabilidade humana calcada em uma consciência revolucionária e subjetividade rebelde. De outro lado, a ameaça dos poderes constituídos que no extremo da barbárie militarizada aniquilam aqueles e aquelas que se insurgem contra a ordem injusta.

No Crato, no Ceará, há 80 anos, o Estado Brasileiro executou mais de 2.000 pessoas com um bombardeio aéreo. Mas como diz o Cordel engajado: "dizem que todo boi de brinquedo ressuscita" (BARROSO, 2002). Assim nasceu Dandara, Guarani Kaiowá, Rosa Leão, Esperança, Vitória, Dom Tomás Balduíno e tantas outras comunidades que hoje resistem ao despejo na Região Metropolitana de Belo Horizonte.

Como diz um Romeiro durante a peça de teatro: Zé Lourenço já tinha avisado: o que eles destruírem aqui, a gente reconstrói acolá, como sempre tinha sido. Sem vingança nem confusão. (ALBINATI; CHIARADIA, 2017, p. 31). Assim, mesmo diante da violência e do aniquilamento perpetrados pelo Estado há várias comunidades que resistem, reexistem e anunciam um novo mundo.

\section{Referências}

ALMEIDA, Maria Isabel Medeiros. Memória e história: o Caldeirão da Santa Cruz do Deserto na narrativa histórica. 2011. 123f. Dissertação (Mestrado) - Pontifícia Universidade Católica de São Paulo, São Paulo, 2011.

BARROSO, Oswald. Auto do Caldeirão - Cordel Engajado. Disponível em: <http://cordelengajado.blogspot.com.br/2012/07/auto-do-caldeiraooswald-barroso_1371.html >. Acesso em: 22 ago. 2017.

BENJAMIN, Walter. O Anjo da História. Organização e tradução de João Barrento. 2. ed. Belo Horizonte: Autêntica Editora, 2013.

BENJAMIN, Walter. Passagens. Organização de Willi Bolle e Olgária Chain Féres Matos. Belo Horizonte: UFMG; São Paulo: Imprensa Oficial do Estado de São Paulo, 2007. 
BOULOS, Guilherme. Por que ocupamos? Uma introdução à luta dos sem-teto. 2. ed. revista e ampliada. São Paulo: Editora Scortecci, 2014.

FUNDAÇÃO JOÃO PINHEIRO. Centro de Estatística e Informação Déficit Habitacional no Brasil 2011-2012: resultados preliminares / Fundação João Pinheiro. Centro de Estatística e Informação - Belo Horizonte, 2014. (Nota técnica, 1) 19 p.: il.

FUNDAÇÃO JOÃO PINHEIRO. Centro de Estatística e Informações Déficit Habitacional municipal no Brasil. / Fundação João Pinheiro. Centro de Estatística e Informações - Belo Horizonte, 2013.

GAGNEBIN, Jeanne Marie. História e narração em Walter Benjamin. São Paulo: Perspectiva, 2004.

LÖWI, Michael. Walter Benjamin: aviso de incêndio: uma leitura das teses "Sobre o conceito de história". São Paulo: Boitempo, 2005.

RICOEUR, Paul. "Memory, history, oblivion" - "Haunting Memories? History in Europe after Authoritarianism". Disponível em: <http://www. uc.pt/fluc/uidief/textos_ricoeur/memoria_historia> . Acesso em: 23 ago. 2017.

Texto do Espetáculo: 'O CALDEIRÃO da Santa Cruz do Deserto'. Concepção: Bruna Chiaradia. Direção: Zé Walter Albinati. Dramaturgia: Raysner de Paula e Zé Walter Albinati. 2017 